\title{
Predicting the throughput of grain products at the multipurpose terminal at the Port of Cape Town
}

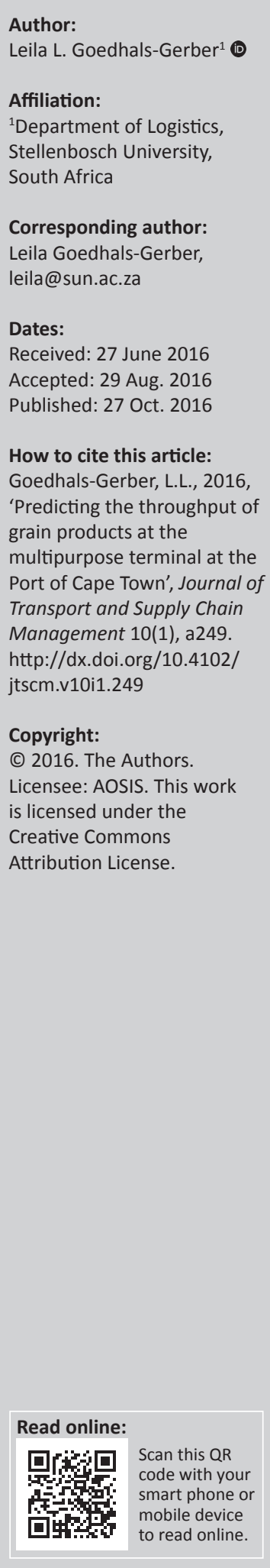

Background: Ports provide vital links in the maritime supply chains on which the trading of countries depend, and their efficiency and performance can contribute largely to the international competitiveness of those countries. However, to achieve and maintain such a contribution, port operators need to understand their role in a national economy and the factors that underlie the efficiency of the intermodal link that ports constitute in international supply chains. One such factor is the capacity of specialised cargo terminals.

Objectives: This article described a possible technique for forecasting the throughput of grain imports through the bulk grain terminal at the Port of Cape Town. It determined whether the capacity in the bulk grain terminal is sufficient to handle current and forecasted volumes of imported grains or whether the volumes justify expansion or upgrading of the bulk grain terminal in the Port of Cape Town.

Method: The Box-Jenkins methodology for autoregressive integrated moving average (ARIMA) models was applied. An ARIMA model - 2 parameter, 1 difference - was selected to do the forecast.

Results: The average tonnage of all grains imported through the Port of Cape Town that can be expected in a month is approximately 90000 tons. The maximum tonnage of all grains imported through the Port of Cape Town that can be expected in a month is approximately 180000 tons.

Conclusion: The analyses show that the demand for imports of grain products at the multipurpose terminal in the Port of Cape Town is not growing substantially. The analyses also identify that the current upper limits of grain imports are within the existing handling and storage capacities of the bulk grain terminal.

\section{Introduction}

One of the primary functions of a port authority is to safeguard that the facilities of the port ensure the rapid turnaround of commercial ships loading and/or offloading cargo. Although a rapid turnaround enables foreign shipowners to raise the productivity of their ships and justifies high port charges to recoup the infrastructure costs involved, providing spare capacity to avoid berthing delays is not an economic option, however desirable that may be to ship operators. The land on which ports bordering cities are constructed is usually extremely valuable, and its opportunity cost is determined largely, if not entirely, by the value of its alternative use for city development. Port authorities or operators of such ports thus need to guarantee that the productivity of port land at least equals that of its alternative use, if the port is to retain its urban location in a free market economy. Accordingly, they must ensure the intensive use of berths.

Although delays in berthing because of insufficient capacity can frustrate the rapid turnaround time of ships and raise the costs of shipping, berth occupancy will be high and so will the productivity of the terminal if the ships are turned around expeditiously through rapid cargo handling. Higher terminal productivity can thus be achieved at the expense of the higher cost of landed goods because of berthing delays, so nullifying the economic benefits. The investment in berths needs to be planned accordingly, by providing sufficient capacity to cope with peak demand and avoid lengthening queues of ships awaiting berths, while ensuring that the berths provided will be well-utilised and idle capacity reduced to a minimum. 
However, the projection of berth occupancy for planning purposes can be difficult when the quantities of agricultural commodities to be handled at grain terminals depend upon seasonal crops, and the statistics for the throughput of such commodities in the past show no identifiable trends. The port authority cannot then rely on statistical regression to project the demand for berths in the future, but must resort to non-parametric techniques. This article concerns one such technique for determining whether the capacity in the bulk grain terminal in the Port of Cape Town is sufficient to handle current and forecasted volumes of imported grains or whether the volumes justify expansion or upgrading of the terminal, which is located adjacent to the Central Business District (CBD) of the city.

\section{Literature review}

\section{Function of a multipurpose terminal}

The Cape Town Multipurpose Terminal (MPT) is used for the import and export of a large variety of commodities including fertiliser, soda-ash, soya, sunflower pellets, wheat, maize, oats, cement and containerised cargo (Transnet Port Terminals 2013). Since the deregulation of the agriculture industry in 1997, traders have been free to source their purchases of bulk grain products from any seller and do so from international suppliers whenever the landed cost is cheaper than the delivered cost of available local produce (Ministry for Agriculture and Land Affairs 1998). The complexity of the influences on the market has resulted in severe volatility in the demand for imported produce, rendering medium and long-term projections difficult (How to feed the world in 2050, 2009). As the grain ships can be offloaded quicker than their cargoes can be removed by rail or road from the terminal, buffer space is required in sheds to store grain temporarily (Fortune 2014). Motor vehicles and loading equipment are required for that purpose, which adds substantially to the transhipment costs (Fortune 2014). Not all the stored grain can be cleared expeditiously because of inadequate storage capacity at the premises of the importers (UNCTAD 2009). Thus, storage at the port terminal provides not only a buffer between the marine and land modes of transport, but also a buffer between delivery by land transport and production at the mill or processing plant. This latter function is unproductive because the opportunity cost of the port land required for such buffering invariably exceeds the opportunity cost of land at the importers' premises (Muller et al. 2009). However, it is difficult to distinguish the cargo that is being held at the port for this purpose and for the terminal operator to charge accordingly as a deterrent (Fortune 2014).

\section{Capacity of the Multipurpose Terminal at the Port of Cape Town}

The MPT at the Port of Cape Town has a design capacity to handle 2.1 million tons of dry bulk per annum, and it has an installed capacity of $1.4 \mathrm{~m}$ tons per annum (Ports Regulator of South Africa 2014/2015). The design capacity of a terminal is the number of tons of cargo that a terminal is designed to handle during a one-year time period (World Bank 2004). A terminal is usually designed to accommodate more capacity than is needed during the initial years of operation. Facilities are then installed to meet the demand for capacity during the initial period, leaving scope for upgrading within the design, that is, installed capacity.

Based on the dry bulk commodities moving through the MPT in 2013 (see Table 1), it is clear that there is sufficient capacity in both the design capacity and installed capacity of the MPT in the Port of Cape Town for the handling of dry bulk.

\section{Throughput}

Cargo throughput is defined by the World Bank (2004) as 'the total number of tons loaded and unloaded in a port in one year', that is, throughput is the total of all import, export, transhipment and transit cargo that passes through the port in one year. According to Talley (2006), the port industry measures optimum port throughput by determining the throughput for which ports are technically efficient (i.e. maximum throughput in the use of resources) for assessing their operations.

\section{Short reviews of the supply chains for imported grain products}

Barley: Over the past few years, variability in rainfall has caused wide fluctuations in barley quality and yields in South Africa (Department of Agriculture, Forestry and Fisheries 2013). Whenever the local crop has fallen short of requirements, barley has been imported mostly from Canada and Australia and, to a lesser extent, from the EU (Department of Agriculture, Forestry and Fisheries 2013). During several seasons, the local supply has far outweighed the demand in quantity, but the high quality of malted barley required for brewing has still necessitated imports (Parker 2009). In these circumstances, import quantities remain largely unpredictable, as shown in Table 2.

Maize: Maize, especially white maize, is South Africa's most important grain product and provides the staple food for millions of the population of Southern Africa. Yellow maize is the most important ingredient in feed rations for dairy, beef, poultry and egg production (Department of Agriculture 2005). Since deregulation, the local maize market has been

\section{TABLE 1: Throughput against design capacity for dry bulk (2013).}

\begin{tabular}{|c|c|c|c|c|c|}
\hline Dry bulk & $\begin{array}{c}\text { Design capacity } \\
\text { (units per annum) }\end{array}$ & $\begin{array}{l}\text { Operational capacity } \\
\text { (units per annum) }\end{array}$ & $\begin{array}{c}2013 / 2014 \\
\text { throughput (mtpa) }\end{array}$ & $\begin{array}{c}\text { Throughput against } \\
\text { design (\%) }\end{array}$ & $\begin{array}{c}\text { Throughput against } \\
\text { installed (\%) }\end{array}$ \\
\hline Cape Town & 2100000 & 1400000 & 646659 & 31 & 46 \\
\hline
\end{tabular}

Source: Ports Regulator of South Africa, 2014/2015, SA port terminals: Capacity and utilisation review 2014/15, viewed 17 June 2016, from http://www.portsregulator.org/images/documents/ South-African-Port-Capacity-and-Utilisation-2014-15.pdf 
unfettered and prices fluctuate with supply and demand as influenced by international maize prices, exchange rates, local production (as influenced by weather conditions and plantings), local consumption, production in the Southern African Development Community and stock levels (both domestic and international) (Department of Agriculture 2005). Consequent upon the influence of these factors, producers negotiate spot, contract or future prices, which fluctuate continuously and result in imports that are largely unpredictable beyond the current season. However, the demand based on anticipated consumption can be forecast (Wright 2012).

Millers are the main buyers of white maize and will import to complement or replace locally produced maize depending on price and quality, subject to exchange rates. The protection afforded by the depreciating rand is an incentive for South African farmers to increase their crops and export the production if local buyers are unwilling to pay the price that then prevails. This sets a price band that influences the volume of imports and adds to its unpredictability.

South Africa imports most of the maize required from Argentina and the USA. Between 11000 and 925000 tonnes were imported during the marketing seasons of 2003/2004

TABLE 2: Barley imports from 2004 to 2015.

\begin{tabular}{lcc}
\hline Market year & Imports (1000 MT) & Growth rate (\%) \\
\hline 2004 & 101 & 55.38 \\
2005 & 79 & -21.78 \\
2006 & 51 & -35.44 \\
2007 & 97 & 90.20 \\
2008 & 99 & 2.06 \\
2009 & 54 & -45.45 \\
2010 & 81 & 50.00 \\
2011 & 49 & -39.51 \\
2012 & 37 & -24.49 \\
2013 & 74 & 100.00 \\
2014 & 92 & 24.32 \\
2015 & 50 & -45.65 \\
\hline
\end{tabular}

Source: United States Department of Agriculture, 2016a, Barley imports, viewed 27 June 2016, from http://www.indexmundi.com/agriculture/?country=za\&commodity=barley\&gra ph=imports

TABLE 3: Imports of maize into South Africa between 2003/2004 and 2014/2015

\begin{tabular}{lc}
\hline Marketing season & Imports \\
\hline $2003 / 2004$ & 441000 \\
$2004 / 2005$ & 219000 \\
$2005 / 2006$ & 360000 \\
$2006 / 2007$ & 931000 \\
$2007 / 2008$ & 1120000 \\
$2008 / 2009$ & 27000 \\
$2009 / 2010$ & 27000 \\
$2010 / 2011$ & 0 \\
$2011 / 2012$ & 421000 \\
$2012 / 2013$ & 11000 \\
$2013 / 2014$ & 79682 \\
$2014 / 2015$ & 65250 \\
\hline
\end{tabular}

Source: SAGIS, 2016, Historic producer deliveries, consumption, imports \& exports, viewed 27 July 2016, from http://www.sagis.org.za/historical\%20prod $\% 20$ consumption $\% 20 \mathrm{imp} \% 20$ exp.html and 2014/2015 as shown in Table 3. Only the marketing season of 2010/2011 had no imports of maize.

The primary maize industry is supported by a secondary industry, which converts maize to either maize-meal for human consumption or animal feed and starch production. Mainly white maize, suitable for human consumption, and yellow maize, for animal feeds (Maize Tariff Working Group Submission 2005), are used for the conversion. Although the market for maize consumption for human purposes seems to be saturated, the animal feed market still shows potential for growth (Capper et al. 2013). In addition, it is expected that the demand for maize required to produce animal feed will rise as the domestic poultry industry continues to expand (see Figure 1).

The expansion of industrial uses of maize is also likely to have a significant impact on the demand for maize in future. The main category of use for maize in the industrial and beverage sectors has been starch sugars and alcohol (Carpenter, Gouse \& Yorobe 2014). These developments could affect the demand for maize imports and require an expansion of the capacity of the grain terminal in the port at Cape Town, but there is insufficient substance in their prediction to take account of the possibilities.

Soya beans: Soya beans are regarded as an economical replacement for maize and also as a crop for the future. In South Africa, soya beans are mainly used for animal feed. Eight percent of the production of soya beans is used for human consumption, $60 \%$ for animal feed (particularly in the broiler and egg industries) and about $32 \%$ for oil and oilcake production. Soy oil ( $18 \%$ of the seed) is processed to specific oil products for use in the food industry (Department of Agriculture, Forestry and Fisheries 2012). The local soya bean production was below the domestic consumption needs for the majority of the period 2002-2011, particularly between the years 2002 and 2008. This situation worsened during 2007 when the domestic consumption requirements far outweighed the domestic production. The situation has, however, improved between the years 2009 and 2011 when the domestic production volumes increased dramatically to

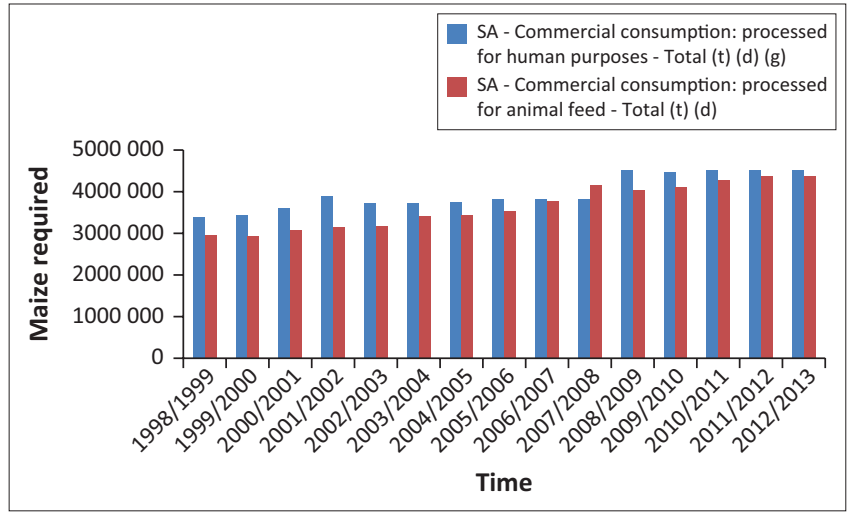

Source: SAGIS, 2014, Products, viewed 18 September 2015, from http://www.sagis.org.za/ products.html

FIGURE 1: The demand for maize required to produce animal feed. 
surpass consumption (Department of Agriculture, Forestry and Fisheries 2012).

The main influences on local soya bean prices include the rate of increase in South American soya bean production, the Chinese demand for imported soya beans, marine freight rates, the value of the rand/dollar exchange rate, the local production rate and the spread of genetically modified cultivars in the main production areas, which could increase yields and help stabilise prices (Department of Agriculture, Forestry and Fisheries 2012).

The imports and exports of soya beans from 2004 to 2015 are shown in Table 4.

Wheat: Although the local wheat market has been deregulated, imports are subject to an ad valorem duty, but are no longer controlled and producers have to compete in the international market. Consequently, prices in South Africa tend to be based on import parity (i.e. the landed cost of international wheat plus the wheat tariff) (Strategy Document for the South African Wheat to Bread Value Chain 2004). Silo owners with capacity that was formerly regulated have now also to compete in a free market with other storers of grain (National Agricultural Marketing Council 2009). The current capacity of the silos is shown in Table 5.

There are currently 684 commercial storage sites for the storage of grain in South Africa, of which 393 are non-grain silo industry sites. In addition, there are 146 non-commercial storage sites (M. Purnell [General Manager: Grain Silo Industry] pers. comm., 2015). Despite being the second most important field crop in South Africa, wheat for human consumption has to be imported in nine out of ten seasons. The quantities imported during the period 1997 to 2013 are shown in Table 6.

TABLE 4: Imports and exports of soya beans from 2004 to 2015.

\begin{tabular}{lcc}
\hline Market year & Imports (1000 MT) & Growth rate (\%) \\
\hline 2004 & 678 & 10.60 \\
2005 & 819 & 20.80 \\
2006 & 967 & 18.07 \\
2007 & 848 & -12.31 \\
2008 & 841 & -0.83 \\
2009 & 1019 & 21.17 \\
2010 & 897 & -11.97 \\
2011 & 682 & -23.97 \\
2012 & 640 & -6.16 \\
2013 & 464 & -27.50 \\
2014 & 510 & 9.91 \\
2015 & 630 & 23.53 \\
\hline
\end{tabular}

Source: United States Department of Agriculture, 2016b, Soyabean imports, viewed 27 June 2016, from $\mathrm{http}: / / \mathrm{www}$.indexmundi.com/agriculture/?country=za\&commodity=soybean meal\&graph=imports

TABLE 5: Capacity of existing grain silos in South Africa.

\begin{tabular}{ll}
\hline Silo owner & Storage capacity \\
\hline Cooperatives (north) & 14.5 million tons \\
Cooperatives (south) & 0.97 million tons \\
Harbours and private owners & 2.1 million tons \\
\hline
\end{tabular}

Source: (M. Purnell [General Manager: Grain Silo Industry] pers. comm., 2015)

\section{The Box-Jenkins methodology}

The Box-Jenkins method follows the following three steps (NCSS 2015):

1. Identification: Graphs of the data, autocorrelations, partial autocorrelations and other information are used to select a class of simple autoregressive integrated moving average (ARIMA) models. This amounts to estimating appropriate values for $p, d$ and $q$, where (Introduction to ARIMA n.d.):

- $\quad p$ is the number of autoregressive terms

- $d$ is the number of non-seasonal differences needed for stationarity

- $q$ is the number of lagged forecast errors in the prediction equation.

2. Estimation: The phis and thetas of the selected model are estimated using maximum likelihood techniques and backcasting. Maximum likelihood estimation (MLE) is a method for estimating the parameters of a statistical model, given data (Kleinbaum \& Klein 2010). Backcasting is a method that starts with defining a desirable future and then works backwards to identify policies and programmes that will connect the future to the present (Brandes \& Brooks 2005).

3. Diagnostic checking: The fitted model is checked for inadequacies by considering the autocorrelations of the residual series (error values).

The steps above are applied iteratively until step three does not produce any improvement in the model (NCSS 2015).

\section{Model identification}

It is important to determine whether the data being analysed exhibit a trend. If so, it is necessary to either fit and remove a

TABLE 6: Wheat imports by South Africa from 1997 to 2013.

\begin{tabular}{lcc}
\hline Market year & Imports (1000 MT) & Growth rate (\%) \\
\hline 1997 & 584 & -26.73 \\
1998 & 585 & 0.17 \\
1999 & 909 & 55.38 \\
2000 & 438 & -51.82 \\
2001 & 561 & 28.08 \\
2002 & 871 & 55.26 \\
2003 & 1278 & 46.73 \\
2004 & 1396 & 9.23 \\
2005 & 1211 & -13.25 \\
2006 & 866 & -28.49 \\
2007 & 1484 & 71.36 \\
2008 & 1402 & -5.53 \\
2009 & 1278 & -8.84 \\
2010 & 1650 & 29.11 \\
2011 & 1724 & 4.48 \\
2012 & 1396 & -19.03 \\
2013 & 1600 & 14.61 \\
2014 & 1832 & 9.83 \\
2015 & 2000 & 9.17 \\
\hline $504 r$ & & \\
\hline
\end{tabular}

Source: United States Department of Agriculture, 2016c, Wheat imports, viewed 27 June 2016, from http://www.indexmundi.com/agriculture/?country=za\&commodity=wheat\&gra $\mathrm{ph}=\mathrm{imports}$ 
deterministic trend or difference the series. Assuming that there is no seasonal variation, the objective of the model identification step is to select values of $d$ and then $p$ and $q$ in the ARIMA $(p, d, q)$ model (Introduction to ARIMA n.d.).

The first step, in either case, is to look at the plots of the autocorrelations and partial autocorrelations. The autocorrelations are then subjected to the tests of both the Box-Pierce $\mathrm{Q}$ and Ljung-Box $\mathrm{Q}^{*}$ statistics in order to determine whether the time series consists of 'white noise'. White noise data are uncorrelated across time with zero mean and constant variance, that is, it has no predictable patterns (Hyndman 2014). If large autocorrelations persist even after several lags, this indicates that either a trend should be removed or the series should be differenced. The next step would be to difference the series (NCSS 2015). Differencing usually reduces the number of large autocorrelations considerably. If the differenced series still does not appear stationary, it is necessary to difference the data again (Introduction to ARIMA n.d.).

It is beneficial to determine the magnitude of a large autocorrelation and partial autocorrelation coefficient. An autocorrelation must be at least $2 / \sqrt{N}$, in absolute value to be statistically significant. By considering the patterns of the autocorrelations and the partial autocorrelations, it is possible to estimate a reasonable model for the data (NCSS 2015).

The identification phase determines the values of $d$ (differencing), $p$ (autoregressive order) and $q$ (moving average order). By studying the two autocorrelation plots, it is possible to estimate these values (NCSS 2015).

\section{Differencing}

The level of differencing is estimated by considering the autocorrelation plots. When the autocorrelation values become insignificant, the appropriate value of $d$ has been identified (NCSS 2015).

\section{Value of $p$}

The value of $p$ is determined from the partial autocorrelations of the appropriately differenced series. If the partial autocorrelations no longer have significant values after a few lags, the last lag with a large value is the estimated value of $p$. If the partial autocorrelations do not decrease to insignificant values, the model is either a moving average model $(p=0)$ or an ARIMA model with positive $p$ and $q$ (NCSS 2015).

\section{Value of $q$}

The value of $q$ is found from the autocorrelations of the appropriately differenced series. If the autocorrelations no longer have significant values after a few lags, the last lag with a large value is the estimated value of $q$. If the autocorrelations remain significant, the model is either an autoregressive model $(q=0)$ or an ARIMA model with a positive $p$ and $q$ (NCSS 2015).

\section{Model estimation and diagnostic checking}

\section{Maximum likelihood estimation}

After estimating the values of $p, d$ and $q$, it is possible to estimate the phis and thetas. The maximum likelihood equation is solved using a non-linear function maximisation algorithm. Backcasting is used to obtain estimates of the initial residuals (NCSS 2015).

\section{Diagnostic checking}

Once a model has been fit, the final step is the diagnostic checking of the model. The checking is carried out by studying the autocorrelation plots of the residuals to check whether any remaining large correlation values can be found. If all the autocorrelations and partial autocorrelations are small, the model is considered adequate and forecasts are generated. If some of the autocorrelations are large, the values of $p$ and/or $q$ are adjusted and the model is reestimated (NCSS 2015).

This process of checking the residuals and adjusting the values of $p$ and $q$ continues until the resulting residuals are all insignificant values. Once a suitable model is selected, forecasts are generated.

\section{Available statistics}

It is evident from the explanation contained in the short reviews of the supply chains for imported grain products that the structure and conduct of the market no longer results in a predictable pattern of import quantities. The influences in the market that result in the unpredictable volatility in those imports are:

- the quality and price of locally produced grain, which depend upon the seasonal success of crops, planting policies of farmers (that are not always rational because of uncertainty about the demand for their produce) and the surpluses carried over from the previous year, as well as the dealings by traders in future deliveries of grain products (WWF 2004)

- the quantity and price (which is likely to be subsidised) of grain produce becoming available seasonally in world markets (The World Bank 1983).

Since the deregulation of the supply of grain produce in South Africa, the complexity of the influences on the market has resulted in such volatility in the demand for imported produce that long- and medium-term projections are no longer feasible. The present fact is that the buyers of grain produce in bulk must project their needs within their planning periods based on statistics of past consumption, allowing for evident changes in preference and population growth (Food and Agriculture Organization of the United Nations 2011). The traders from whom they acquire the produce usually respond to immediate market circumstances without predicting their imports beyond those involved in the transactions in which they are engaged (Food and Agriculture Organization of the United Nations 2011). 
Consequently, they have little use for historic data. In these circumstances, monthly quantities of grain imports through the Port of Cape Town are not likely to conform to any pattern, but will vary randomly.

That contention is ascertained by the analysis contained in the statistical analysis section, using the Box-Jenkins forecasting methodology for ARIMA models. In accordance with that methodology, the assumption is made that the monthly quantities of the various grain products imported through the bulk grain terminal at Cape Town, during the period for which reliable data are available, vary randomly (i.e. comprise 'white noise' in terms of the formulation of the ARIMA models). Tests are then conducted to determine whether that assumption is false by examining the relationships between successive monthly imports and imports lagged by one or more months. If there is a relationship between the quantities of imports in any of the months examined (i.e. if there is a semblance of a recurrent pattern or trend - for example, if the monthly volumes increase), the statistical analysis enables the calculation of the extent to which the assumption of randomness is probably wrong and the determination of whether that probability is sufficiently significant to reject the assumption of randomness. As calculated in statistical analysis, the assumption cannot be rejected for the grains examined, whereas the short reviews of the supply chains for imported grain products provide a rational explanation for the randomness.

The conclusion reached does not eliminate the use of the statistical analysis for planning purposes. As the assumed randomness of the statistics of imported grain produce is substantiated by the low probability of that assumption being wrong, the probability of the monthly imports significantly exceeding the monthly imports on which the conclusion of randomness is based can also be calculated (i.e. if the quantities of monthly imports in the past are shown to be random because no significant deviation from randomness in the quantities observed could be detected), then the probability of the monthly imports not deviating significantly in the future (i.e. the probability that future import volumes will not exceed the standard deviation of the basic series of monthly import statistics) can also be calculated. That enables the probable upper and lower limits of the monthly import volumes to be estimated. Although the proof of randomness precludes the prediction that the most likely monthly quantity of imports will lie midway between the upper and lower limits, it is logical to regard that quantity as the best estimate. (It would be the best estimate if the variation in the monthly quantities of imports conformed statistically to a normal distribution, but that conflicts with the concept of randomness, necessitating the conclusion that any quantity between the upper and lower limits is likely to be imported in any month.) However, for planning purposes only the upper limit is of interest, for it is the quantity for which provision should be made if the capacity of the terminal is seldom to be exceeded. By accepting a higher or lower probability that the monthly imports will not exceed a limit, the limit is in fact raised or lowered.

\section{Methodology}

In the endeavour to calculate the capability of the MPT at the Port of Cape Town to handle grain imports, secondary data obtained from Transnet National Port's Authority were analysed. Data revealing grain imports from April 2004 to May 2015 were scrutinised to establish any seasonal, trend or cyclical patterns. Data on actual grain imports serve as the most accurate source of data as they provide a true reflection of grain product imports over a specific period of time.

In this article, grain product imports included imports of soya, maize, barley, wheat and oats extending over a 134-month period from April 2004 to May 2015. The basic data that could be acquired did not allow the calculation of unbroken time series for sufficiently long periods to enable the extrapolation of trends. In addition, it was evident not only that trends are unidentifiable, but that trends did not exist. Consequently, it was necessary to resort to other statistical techniques to forecast the capacity requirements at the MPT at the Port of Cape Town. The methodology adopted was to apply the Box-Jenkins methodology for autoregressive integrated moving average (ARIMA) models.

The Box-Jenkins methodology applied to ARIMA models is a technically sophisticated method of forecasting a variable by analysing only the past pattern of the time series. It ignores information that might be needed to devise a structural regression model, but instead uses the most recent observation of the variable to be forecast as a starting value and proceeds to analyse potential forecasting errors in order to elect the most appropriate adjustment for future time periods (Wilson, Keating \& John Galt Solutions Inc. 2007). The main advantage of the Box-Jenkins methodology is that it allows consideration of several different forecasting models in order to enable the best model to be chosen.

\section{Statistical analysis}

The Box-Jenkins methodology for ARIMA models consists of three phases, namely identification, estimation and testing, and application. The approach is outlined in Figure 2.

The forecast undertaken is for all grains imported through the MPT at the Port of Cape Town. Tonnages imported between April 2004 and May 2015 were plotted, as shown in Figure 3.

The next step is the calculation of the autocorrelations (Figure 4) and partial autocorrelations (Figure 5) of the time series. The autocorrelations and partial autocorrelations are calculated to determine whether they have significant values. The autocorrelations are then subjected to the tests of both the Box-Pierce $Q$ and Ljung-Box $Q^{*}$ statistics in order to determine whether the time series consists of 'white noise'.

Figure 4 shows that some of the autocorrelation values are significant after 24 lags, and Figure 5 identifies that some of the partial autocorrelation values are significant after 24 lags. 


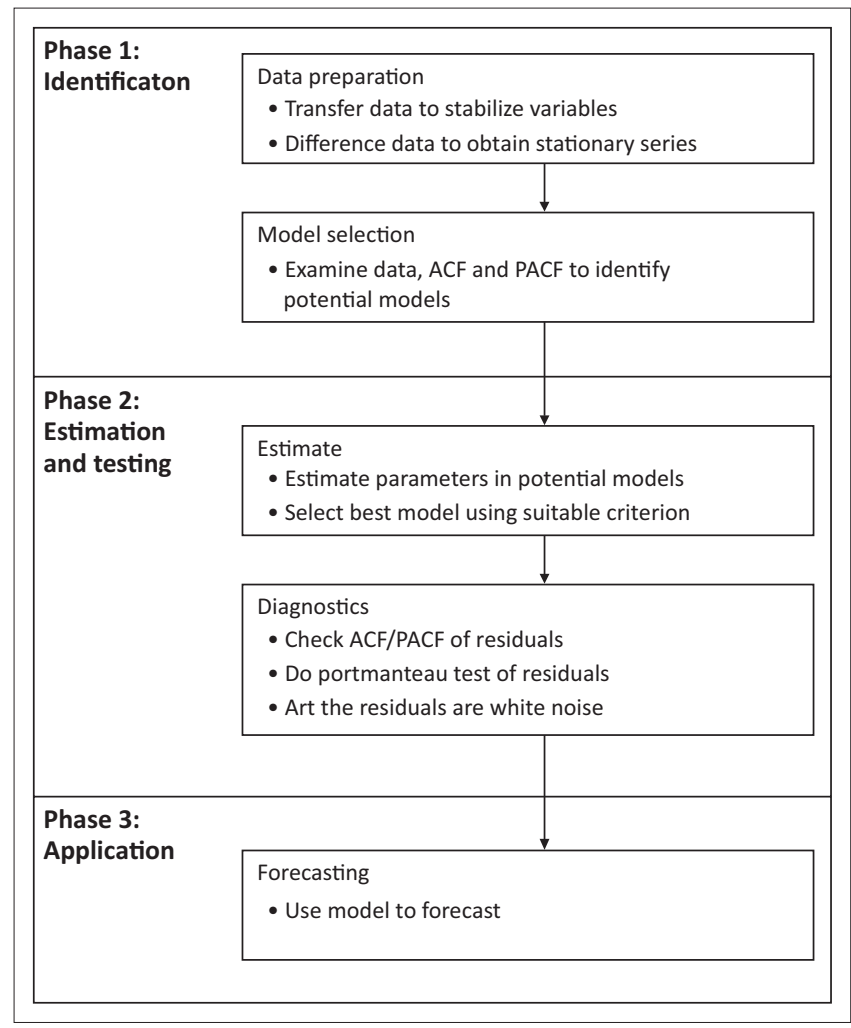

Source: Makridakis, S., Wheeleright, S.C. \& Hyndman, R.J., 1998, Forecasting methods and applications, 3rd edn., John Wiley \& Sons, Inc., New York

FIGURE 2: Schematic representation of the Box-Jenkins methodology for time series modelling.

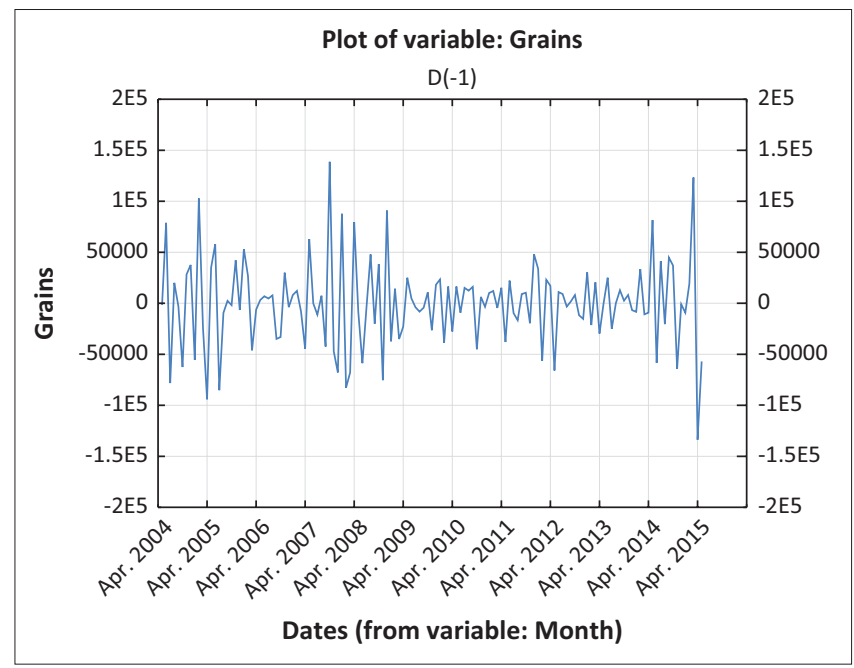

FIGURE 3: Tonnages of grains imported through the bulk grain terminal in the Port of Cape Town between April 2004 and May 2015.

This meant that the data needed to be differenced. After differencing the data, it was checked again for white noise.

Once white noise was confirmed, various models were applied to the time series in order to choose the best model. An ARIMA model - 2 parameter, 1 difference - was selected to do the forecast. In order to confirm that the model is appropriate, the autocorrelations (Figure 6) and partial autocorrelations (Figure 7) of the time series are again calculated and tested against the Box-Pierce $Q$ and Ljung-Box Q* statistics.

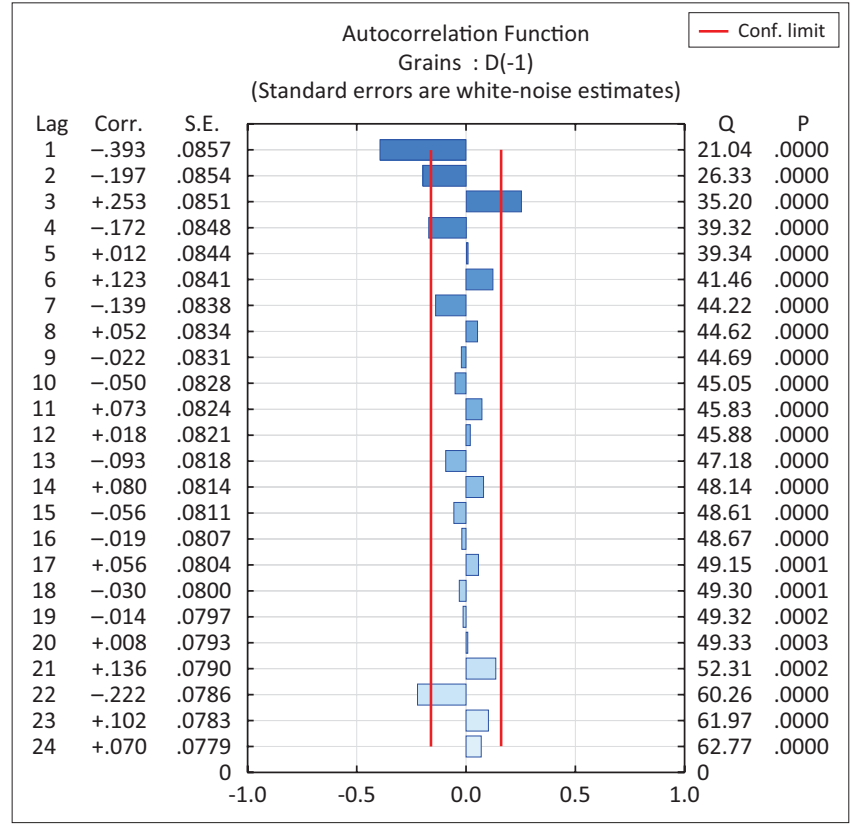

FIGURE 4: Autocorrelation function for grains.

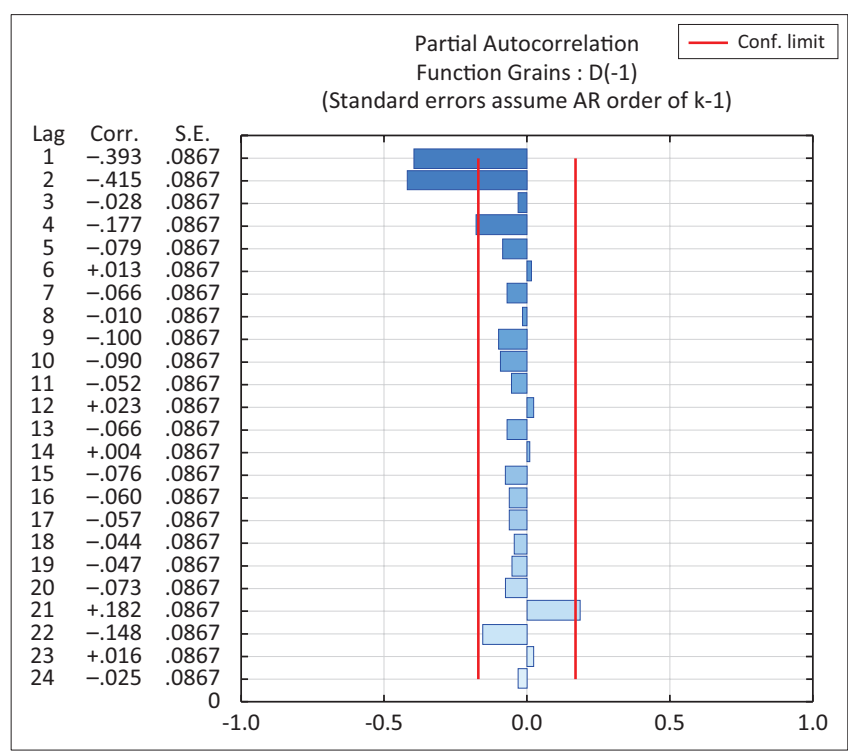

FIGURE 5: Partial autocorrelation for grains.

From Figures 6 and 7, it is clear (because all the autocorrelations and partial autocorrelations are small) that an appropriate model has been selected. That was then used to forecast the tonnages of grain imports per month through the MPT at Port of Cape Town. However, from Figure 8 it will be seen that the statistical package used gives the lower limit as negative values, which cannot apply. The lower limit has, therefore, been increased to zero and a new forecast calculated as shown in Figure 9. (The format in Figure 9 is different from Figure 8 as the graph was drawn using Excel rather than Statistica.) That does not cause any problem as long as only the upper limit is the main concern, being the probable maximum capacity required in future on the basis of the data available for past imports. According to the forecast, the maximum tonnage of all grains imported through the Port of Cape Town that 


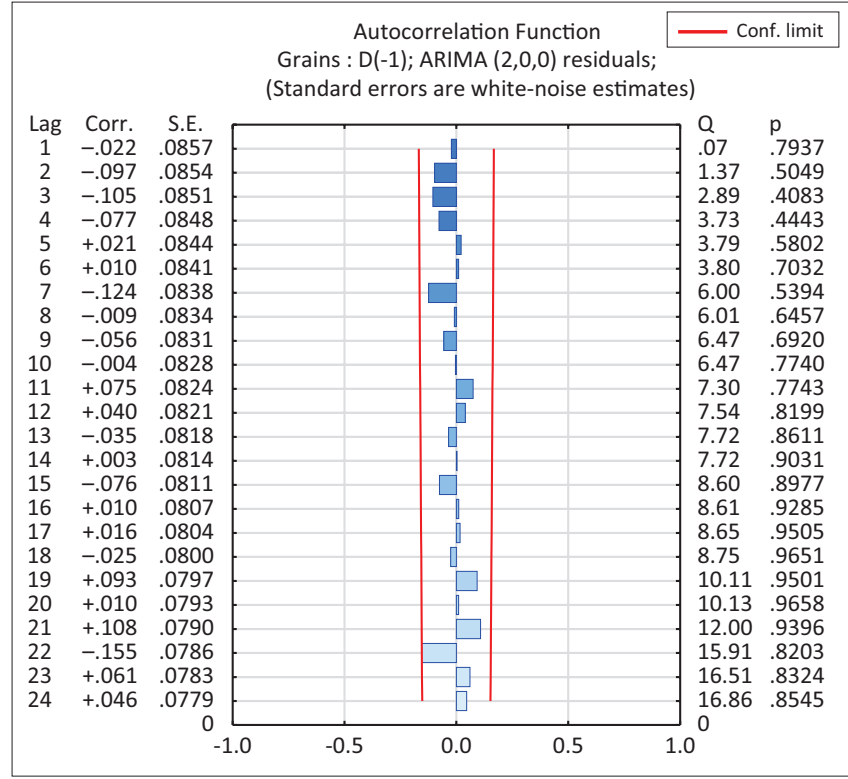

FIGURE 6: Autocorrelation function for grains for the chosen model.

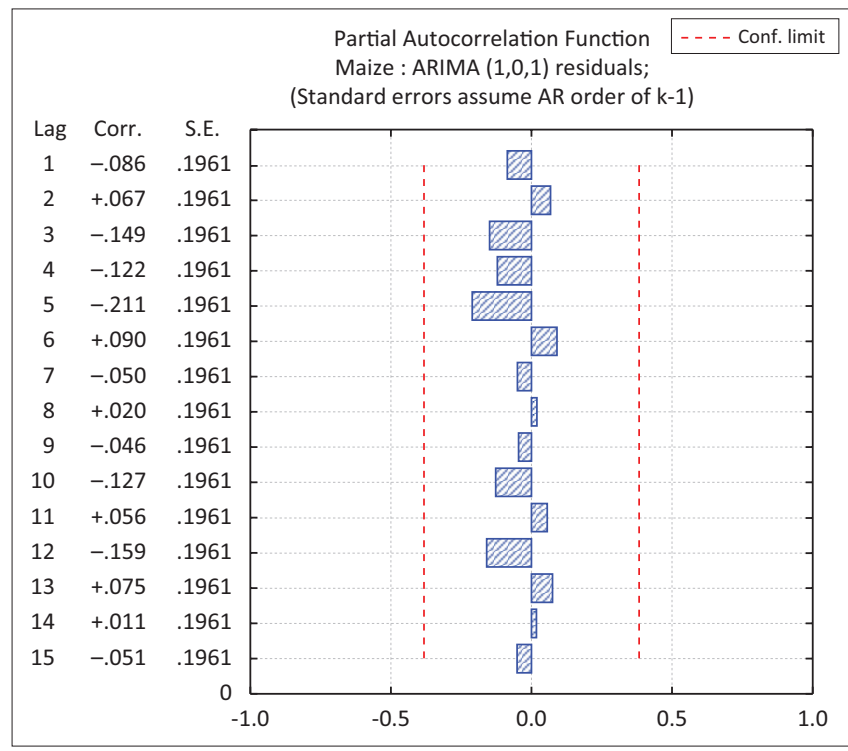

FIGURE 7: Partial autocorrelation function for grains for the chosen model.

can be expected in a month is approximately 180000 tons. However, the average tonnage of all grains imported through the Port of Cape Town that can be expected in a month is approximately 90000 tons.

\section{Conclusion}

The analysis of the statistics on past imports of grain products at the MPT in the Port of Cape Town shows that the demand for grain imports is not growing significantly. That conclusion is in accordance with a rational explanation of the market circumstances, taking account of domestic demand and production, as well as international supply and pricing.

The analyses show that the imports of grain products through the MPT in the Port of Cape Town do not vary according to an identifiable trend or seasonal fluctuation,

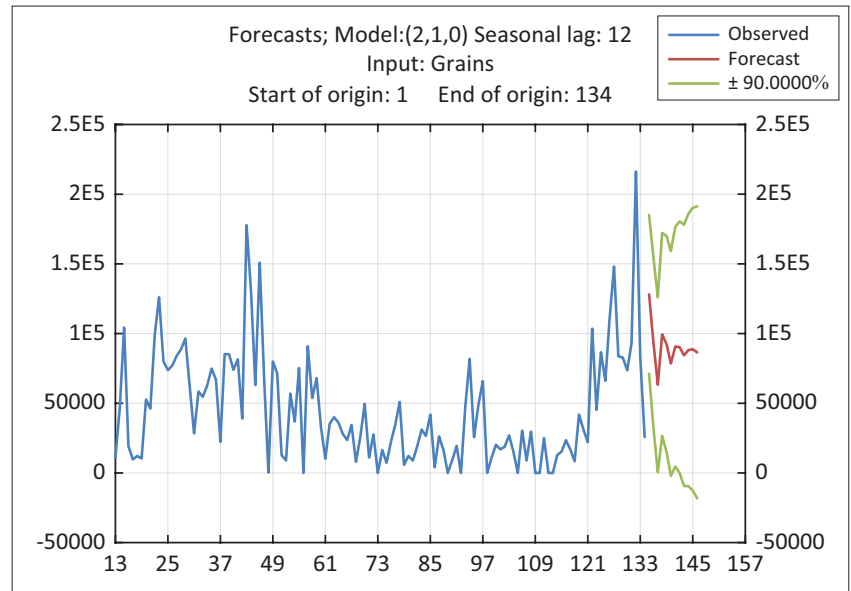

FIGURE 8: Original forecast of maize imports through the bulk grain terminal in the Port of Cape Town.

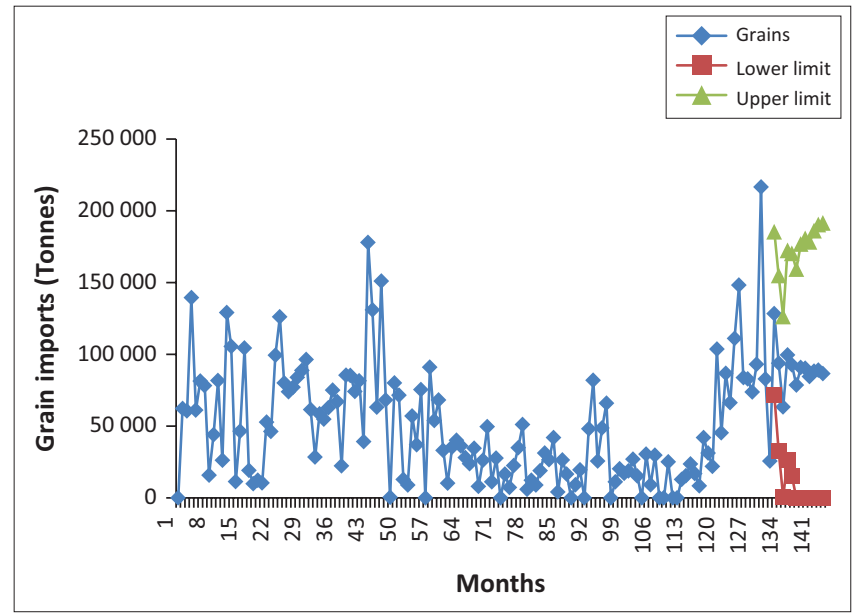

FIGURE 9: Adjusted forecast of grain imports through the bulk grain terminal in the Port of Cape Town.

but vary randomly. The analyses also show that the historic imports of grains through the MPT are within the design capacity of $2.1 \mathrm{~m}$ tons per annum and the installed capacity of $1.4 \mathrm{~m}$ tons per annum. In addition, the analyses identify the probable upper limits of the monthly imports to be estimated for at least the next few years. Those limits are within the existing handling and storage capacities of the bulk grain terminal.

This article identifies a possible technique that can be used to forecast when the historic data for commodities show no identifiable trends, that is, vary randomly. The technique can be applied to commodities, other than grains. It would be beneficial to repeat the research in the future when more data are available. The reliability of forecasting improves with an increase in historic data. Additional possible research includes applying the Box-Jenkins method to other commodities being imported through the port, for example, deciduous or citrus fruit.

\section{Acknowledgements}

The author would like to acknowledge Professor Daan Nel from the Centre for Statistical Analysis at Stellenbosch University for his assistance with the statistical analyses. 


\section{Competing interest}

The author declares that she has no financial or personal relationship(s) that may have inappropriately influenced her in writing this article.

\section{References}

Brandes, O.M. \& Brooks, D.B., 2005, The soft path for water in a Nutshell, A joint publication of Friends of the Earth Canada and the POLIS Project on Ecological Governance, University of Victoria, Victoria, BC.

Capper, J.L., Berger, L., Brashears, M.M. \& Jensen, H.H., 2013, 'Animal feed vs. human food: Challenges and opportunities in sustaining animal agriculture toward 2050',
viewed 02 July 2016, from http://www.cast-science.org/download.cfm?Publicati viewed 02 July 2016, from http://www.cast-science.org/download.
onID=278268\&File=1e30d1bf7a7156ce24b3154cc313b587d97bTR

Carpenter, J., Gouse, M. \& Yorobe J. Jr., 2014, 'Maize / Corn', in S.J. Smyth, P.W.B. Phillips \& D. Castle (eds.), Handbook on agriculture, biotechnology and development, pp. 583-612, Edward Elgar Publishing Limited, Cheltenham, UK.

Department of Agriculture, 2005, Trends in the agricultural sector, viewed 15 June 2016, from http://www.nda.agric.za/docs/Trends_2005.pdf

Department of Agriculture, Forestry and Fisheries, 2012, Soybean market value chain profile, viewed 24 May 2016, from http://www.nda.agric.za/docs/AMCP/ Soyab2012.pdf

Department of Agriculture, Forestry and Fisheries, 2013, Trends in the agricultura sector, viewed 10 July 2016, from http://www.nda.agric.za/docs/statsinfo/ Trends13.pdf

Food and Agriculture Organization of the United Nations, 2011, The state of food insecurity in the world. How does international price volatility affect domestic economies and food security?, viewed 13 June 2016, from http://www.fao.org/ docrep/014/i2330e/i2330e.pdf

Fortune, P., 2014, Terminal Manager: Multipurpose Terminal. Personal Interview. Port of Cape Town, Cape Town.

Goldblatt, A., 2004, Agriculture: Facts \& trends South Africa, viewed 02 July 2016 from http://awsassets.wwf.org.za/downloads/facts_brochure_mockup_04_b.pdf

How to feed the world in 2050, 2009, viewed 16 May 2016, from http://www.fao.org/ fileadmin/templates/wsfs/docs/expert_paper/How_to_Feed_the_World in_2050.pdf

Hyndman, R.J., 2014, Forecasting: Principles \& practice, viewed 23 May 2016, from http://robjhyndman.com/uwafiles/fpp-notes.pdf

Introduction to ARIMA, n.d., viewed 02 July 2016, from http://people.duke. edu/ rnau/411arim.htm

Kleinbaum, D.G. \& Klein, M., 2010, 'Maximum likelihood techniques: An overview', in M. Gail, K. Krickeberg, J.M. Samet, A. Tsiatis \& W. Wong (eds.), Logistic regression, Part of the series Statistics for Biology and Health, pp. 103-127, Springer, New York.

Maize Tariff Working Group Submission, 2005, Maize tariff investigation: Questionnaire generic information on the maize industry, viewed 14 June 2006, from http:// www.grainmilling.org.za/_document/Maize\%20TARIFF\%20Inv\%20Gen $\% 204$. doc

Makridakis, S., Wheeleright, S.C. \& Hyndman, R.J., 1998, Forecasting methods and applications, 3rd edn., John Wiley \& Sons, Inc., New York.

Ministry for Agriculture and Land Affairs, 1998, Agricultural policy in South Africa, viewed 03 June 2016, from http://www.nda.agric.za/docs/Policy/policy98.htm
Muller, G., Smith, K., Sessions, P. \& Gevers, R., 2009, Economic status Quo assessment: A local area plan and land use management scheme for the back of port interface zone, viewed 03 June 2016, from https://www.durban.gov.za/Resource Centre/ zone, viewed 03 June 2016, from https://www.durban.gov.za/Resource_Centre/ Ch1-BoP-Economic(310209).pdf

National Agricultural Marketing Council, 2009, The functioning of the agricultural futures market for grains and oilseeds in the light of concerns expressed by GrainSA, viewed 17 May 2016, from www.namc.co.za/Functioning\%200 $\% 20$ the $\% 20$ Agricultural $\% 20$ Futures $\% 20$ Market

NCSS, 2015, Time series and forecasting methods in NCSS, viewed 20 June 2016, from http://www.ncss.com/software/ncss/time-series-and-forecasting-inncss/\#ARIMA

Parker, A.C., 2009, 'A qualitative study of key success factors for multinational corporations operating in sub-Saharan Africa', Master's thesis, Stellenbosch University, Stellenbosch.

Ports Regulator of South Africa, 2014/2015, SA port terminals: Capacity and utilisation review 2014/15, viewed 17 June 2016, from http://www.portsregulator.org/ images/documents/South-African-Port-Capacity-and-Utilisation-2014-15.pdf

SAGIS, 2014, Products, viewed 18 September 2015, from http://www.sagis.org.za/ products.html

SAGIS, 2016, Historic producer deliveries, consumption, imports \& exports, viewed 27 July 2016, from http://www.sagis.org.za/historical\%20prod $\% 20$ consumption $\% 20$ imp\%20exp.html

Strategy Document for the South African Wheat to Bread Value Chain, 2004, viewed 15 June 2016, from http://www.grainmilling.org.za/_document/WHEAT\%20 Strategy\%20(April\%202004).doc

Talley, W.K., 2006, Optimum port throughput, viewed 10 July 2016, from http:// ageconsearch.umn.edu/bitstream/208010/2/2006_4A_OptPort_paper.pdf

Transnet Port Terminals, 2013, Cape Town Terminal, viewed 10 June 2016, from http://www.transnet-tpt.net/Ports/Pages/CapeTown_Multi.aspx

UNCTAD, 2009, Development impacts of commodity exchanges in emerging markets, viewed 10 June 2016, from http://unctad.org/en/Docs/ditccom20089_en.pdf

United States Department of Agriculture, 2016a, Barley imports, viewed 27 June 2016, from http://www.indexmundi.com/agriculture/?country=za\&commodity= barley\&graph=imports

United States Department of Agriculture, 2016b, Soyabean imports, viewed 27 June 2016, from http://www.indexmundi.com/agriculture/?country=za\&commodity=s oybean-meal\&graph=imports

United States Department of Agriculture, 2016c, Wheat imports, viewed 27 June 2016, from http://www.indexmundi.com/agriculture/?country=za\&commodity= wheat\&graph=imports

Wilson, J.H., Keating, B. \& John Galt Solutions, INC, 2007, Business forecasting with accompanying excel-based forecastX software, 5th edn., McGraw-Hil International, New York.

World Bank, 1983, Marketing functions, markets, and food price formation, viewed 14 June 2016, from http://web.stanford.edu/group/FRI/indonesia/documents/ foodpolicy/chapt4.fm.html

World Bank, 2004, Core port and transport logistic measures: Definitions, priorities, and sources of data, viewed 14 June 2016, from http://www.worldbank.org/ transport/transportresults/coremeasures/cm-ports.pdf

Wright, B.D., 2012, International grain reserves and other instruments to address volatility in grain markets, viewed 12 July 2016, from http://wbro.oxfordjournals. org/content/27/2/222.full

WWF, 2004, Agriculture: facts \& trends for South Africa, viewed 11 August 2016, from http://awsassets.wwf.org.za/downloads/facts_brochure_mockup_04_b.pdf 